\title{
Fibroma of tendon sheath
}

\author{
PS SMITH, AS PIETERSE, J MCCLURE
}

From the Adelaide Bone and Joint Research Unit, Division of Tissue Pathology, Institute of Medical and Veterinary Science, Frome Road, Adelaide, South Australia 5000

SUMMARY A series of nine cases of fibroma of tendon sheath is described including details of the ultrastructural features of two cases. The series was composed of lesions from six males and three females with a mean age of $38 \mathrm{yr}$. The most common site of involvement was the hand (including fingers) and the mean greatest diameter was $19 \mathrm{~mm}$. Typically the tumours were lobulated and microscopically there was a collagenous stroma with spindle and stellate cells in a moderate degree of cellularity. One recurrence was noted in the series. The lesion was distinguished from circumscribed fibromatosis, nodular fasciitis, neurofibroma, leiomyoma, scar tissue, giant cell tumour of tendon sheath (localised nodular tenosynovitis) and fibrous histiocytoma. Ultrastructural studies revealed that the large majority of cells present in the two cases studied were myofibroblasts and fibroma of tendon sheath is therefore the third instance of a benign tumour containing these cells (the other two being dermatofibroma and giant cell fibroma of the oral mucosa).

In his classification of tumours of tendon sheath Buxton ${ }^{1}$ considered that benign tumours included (i) lipoma, (ii) fibroma, (iii) chondroma and (iv) ganglion. Obviously the latter would not be considered a true neoplasm and the other three at first sight would be considered rare. Buxton also referred to a "giant celled myeloma" which was benign but liable to recur locally. It is obvious that this entity equates to the so-called giant cell tumour of tendon sheath a lesion which is probably not a true neoplasm and which is best regarded as a nodular tenosynovitis being a reactive proliferation of both $\mathrm{A}$ and $\mathrm{B}$ tenosynoviocytes. ${ }^{2}$ Buxton regarded tendon sheath fibroma as uncommon and described a specimen from near the ankle and which was in the Museum of the Royal College of Surgeons of England. Geschickter and Copeland ${ }^{3}$ described a fibroma of tendon sheath as an encapsulated tumour composed of tightly packed spindle cells surrounded by collagen fibres.

From 1936 to 1979 no additional cases of fibroma of tendon sheath were reported in the literature until Chung and Enzinger ${ }^{4}$ described the clinical, macroscopic and light microscopical characteristics of this tumour. They described a well circumscribed often lobulated tumour which was usually attached to tendon or tendon sheath. Microscopically there was dense fibrocollagenous tissue containing usually

Accepted for publication 9 December 1981 spindle but sometimes stellate cells and frequently bearing dilated or slit-like vascular channels some of which resembled tenosynovial spaces. In the last few years we have had experience of nine cases of tendon sheath lesions which fulfil the diagnostic criteria of fibroma as laid down by Chung and Enzinger. Our experience with these lesions is reported here in view of the fact that the majority were not initially recognised as fibromas and that electron microscopical studies were performed in two cases.

\section{Material and methods}

All tendon sheath lesions accessioned to the Division of Tissue Pathology of the IMVS over the 10year-period 1971-80 were reviewed and nine cases were identified which exhibited features consistent with a diagnosis of fibroma. Haematoxylin and eosin (HE) stained sections were available in each case. In addition the following special stains were applied (i) Perl's Prussian blue, (ii) Masson's trichrome, (iii) Gordon and Sweet's reticulin, (iv) PAS, (v) PAS after diastase digestion, (vi) MSB, (vii) alcian blue ( $\mathrm{pH} 2.5$ ), (viii) Miller's elastin stain and (ix) von Kossa. In two cases portions of formalin-fixed tissue were post-fixed in osmium tetroxide and processed into Spurr's resin. Survey sections were cut and representative blocks were thinsectioned for electron microscopy.

A limited amount of clinical data was abstracted 
Clinical and macroscopic data of nine cases of fibroma of tendon sheath

\begin{tabular}{|c|c|c|c|c|c|}
\hline Case & Sex & Age & Site & Clinical history & Macroscopic appearance \\
\hline 1 & $\mathbf{M}$ & 41 & Not known & Not known & $\begin{array}{l}\text { An encapsulated white nodule } \\
20 \times 10 \times 10 \mathrm{~mm}\end{array}$ \\
\hline 2 & $\mathbf{M}$ & 48 & Palm of left palm & Swelling after injury & $\begin{array}{l}\text { Irregular, firm grey nodule } 26 \mathrm{~mm} \text { in } \\
\text { maximum diameter }\end{array}$ \\
\hline 3 & $\mathbf{F}$ & 26 & $\begin{array}{l}\text { Palmar aspect of left } \\
\text { middle finger }\end{array}$ & Not known & Fibrous nodule size unknown \\
\hline $\begin{array}{l}4 \\
5 \\
6 \\
7\end{array}$ & $\begin{array}{l}\mathbf{F} \\
\mathbf{M} \\
\mathbf{M} \\
\mathbf{F}\end{array}$ & $\begin{array}{l}68 \\
23 \\
18 \\
29\end{array}$ & $\begin{array}{l}\text { Back of the left hand } \\
\text { Not known } \\
\text { Right middle finger } \\
\text { Extensor tendon } \\
\text { apparatus of left hand }\end{array}$ & $\begin{array}{l}\text { Cystic swelling } \\
\text { Not known } \\
\text { Not known } \\
\text { Described as a ganglion }\end{array}$ & $\begin{array}{l}\text { Firm, white nodule } 25 \times 25 \times 20 \mathrm{~mm} \\
\text { Not known } \\
\text { Ovoid white nodule } 20 \times 15 \times 15 \mathrm{~mm} \\
\text { White nodule } 7 \times 5 \times 2 \mathrm{~mm}\end{array}$ \\
\hline & 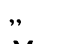 & $"$ & Recurrence of above & , & Irregular greyish tissue $12 \times 8 \times 5 \mathrm{~mm}$ \\
\hline 8 & $\mathbf{M}$ & 58 & $\begin{array}{l}\text { Ulnar aspect of distal } \\
\text { phalanx of left index } \\
\text { finger }\end{array}$ & $\begin{array}{l}\text { Swelling present for a few } \\
\text { months. Not painful }\end{array}$ & $\begin{array}{l}\text { Firm, white nodule } 12 \times 18 \times 10 \mathrm{~mm} \\
\text { Weight }=1.6 \mathrm{~g}\end{array}$ \\
\hline 9 & $\mathbf{M}$ & 33 & Left knee & $\begin{array}{l}\text { Smooth rounded tumour } \\
\text { attached to quadriceps } \\
\text { mechanism }\end{array}$ & Firm, white nodule $30 \times 20 \times 10 \mathrm{~mm}$ \\
\hline
\end{tabular}

from the information submitted with each biopsy and this is shown in the Table.

\section{Results}

An examination of the clinical data shows that in the nine cases there was one recurrence making 10 specimens available for examination. There were six males and three females in the series. The mean age was $38 \mathrm{yr}$ (range 18-68 yr). The lesion was related to the knee in one case and to the hand in six instances. Three of these were related to fingers and three to either the palmar or dorsal aspects of the hand.

The mean greatest diameter was $19 \mathrm{~mm}$ (range 7-30 $\mathrm{mm}$ ) and in seven specimens there was a distinct lobulation. In one case mucoid areas were seen macroscopically and in one other microscopically. Microfoci of cystic change were noted in two specimens. Generally the stroma was markedly collagenous (confirmed by the trichrome strain) and the majority of constituent cells were spindle-shaped (Figs 1,2). Blood vessels were evenly dispersed throughout in nine instances and only in one were slit-like spaces prominent. Limited areas of looser, less fibrous stroma were seen in six samples and the constituent cells were here stellate in shape (Fig. 3). Assessment of the overall degree of cellularity revealed it to be mild in three, moderate in five and marked in two specimens. Extravasation of erythrocytes (in small numbers) was seen in three cases. Occasional multinucleated giant cells (macrophage polykaryons) were seen in one case. Foam cells were not seen in any of the cases studied. There was no significant mitotic activity.

Small foci of mucoid change were seen in two cases and these areas were shown to contain an acid mucin. In two other cases there were small areas exhibiting a storiform pattern. There was a fine reticulin pattern with fibres apparent around individual cells in all cases. A small amount of haemosiderin was present in three specimens but there was never any detectable fibrin. No elastin was seen in the lesions and the von Kossa stain was uniformly negative. True encapsulation was not seen. In several cases there was condensation of marginal connective tissue giving the appearance of a pseudocapsule.

Ultrastructural studies were performed on two of the cases and identical features were seen in both. Sections revealed spindle and stellate cells set in a collagen matrix. The nuclei varied from regular and elongated to highly convoluted the latter being much frequent (Fig. 4). Chromatin was marginated and a prominent nucleolus was only occasionally seen. The cytoplasm contained large amounts of rough endoplasmic reticulum which was often dilated by an amorphous substance. Free ribosomes occurred in large numbers but only an occasional swollen mitochondrion was seen. There were also large vacuoles present which appeared to have contained lipid. Fine myofilaments were visible just beneath the cell surface and occasional larger bundles were seen between the organelles of some cells (Fig. 5).

At higher magnification these myofilament bundles exhibited periodic densities indicating their similarity to actin (Fig. 6). The cell surface tended to be indistinct but no cell-cell or cell-stroma (hemidesmosomes on a basal lamina) junctions were seen. Occasional groups of pinocytotic vesicles were visible however (Fig. 7). Clefts frequently occurred between the collagen and the cells and between neighbouring cells (Fig. 4). These clefts were not bounded by a basement membrane and cell cytoplasm rarely extended around their entire internal 


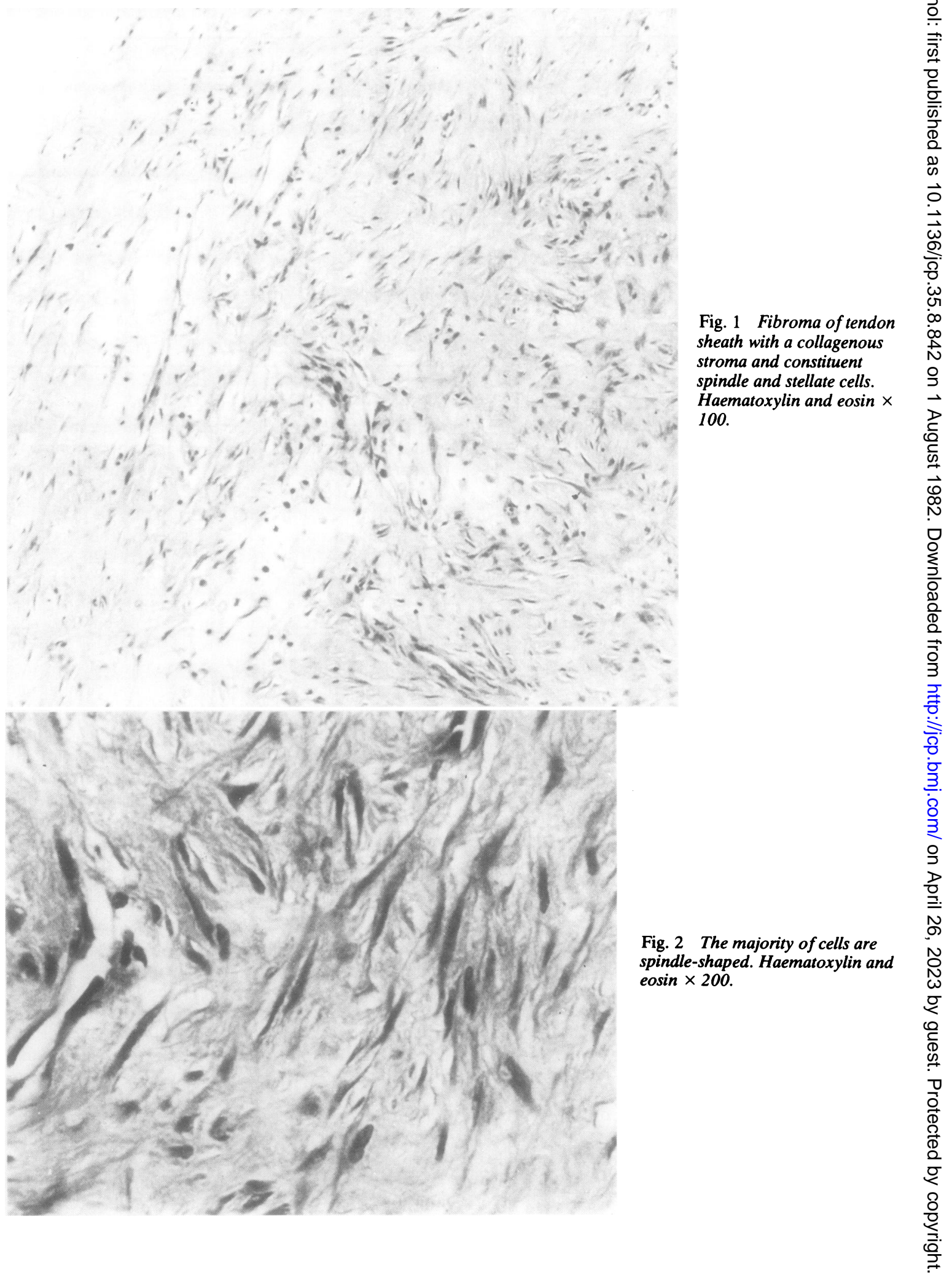




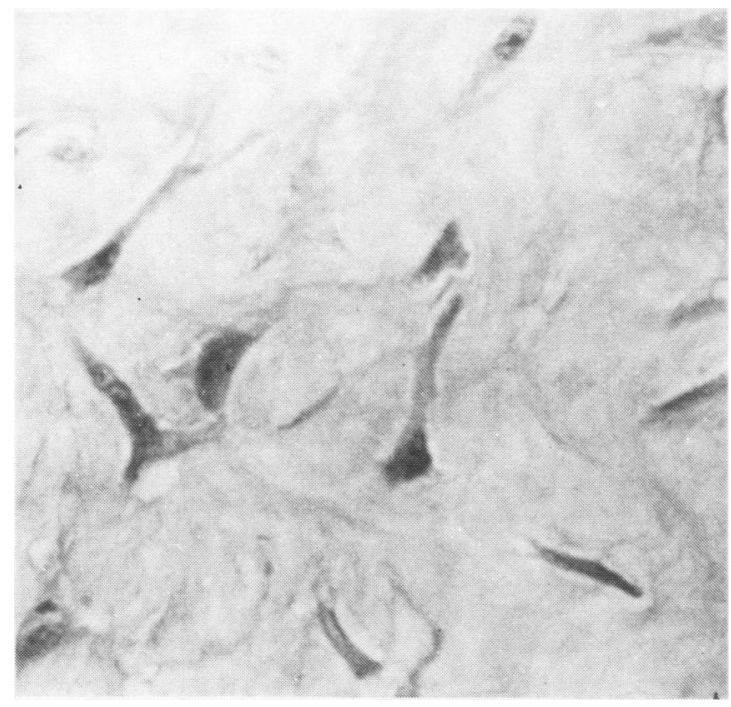

Fig. 3 Less frequent stellate cells are illustrated. Haematoxylin and eosin $\times 400$.

circumference. No erythrocytes were seen in these structures.

\section{Discussion}

The clinical data were limited in this series but in agreement with the findings of Chung and Enzinger ${ }^{4}$ the lesion was more common in males than females and the fingers and hands were most commonly affected. The mean age in the present series was $38 \mathrm{yr}$ compared to a median of $31 \mathrm{yr}$ in that of Chung and Enzinger. The mean diameter was $19.0 \mathrm{~mm}$ compared to a median of $18.0 \mathrm{~mm}$. Only in one case was there recurrence of the lesion (five months after initial excision). This is considerably less than the recurrence rate of $24 \%$ reported by Chung and Enzinger but their series was much larger and follow-up was for a considerably longer period of time.

In determining the typical features of fibroma of tendon sheath it is evident that a collagenous stroma generally containing spindle cells in a moderate degree of cellularity were the dominant features.

Blood vessels were fairly prominent in a majority and in $80 \%$ an attachment to tendon sheath was evident. Lobulation was observed in $70 \%$. Foci of stellate cells were observed in $60 \%$ of cases. These represented the main diagnostic features and were similar to the criteria developed by Chung and Enzinger except that slit-like spaces were infrequent in the present series.

In a consideration of the differential diagnosis of these lesions one must exclude circumscribed fibromatosis, nodular fasciitis, neurofibroma, leiomyoma, scar tissue, giant cell tumour of tendon sheath (localised nodular tenosynovitis) and fibrous histiocytoma. Distinction from nodular fasciitis and

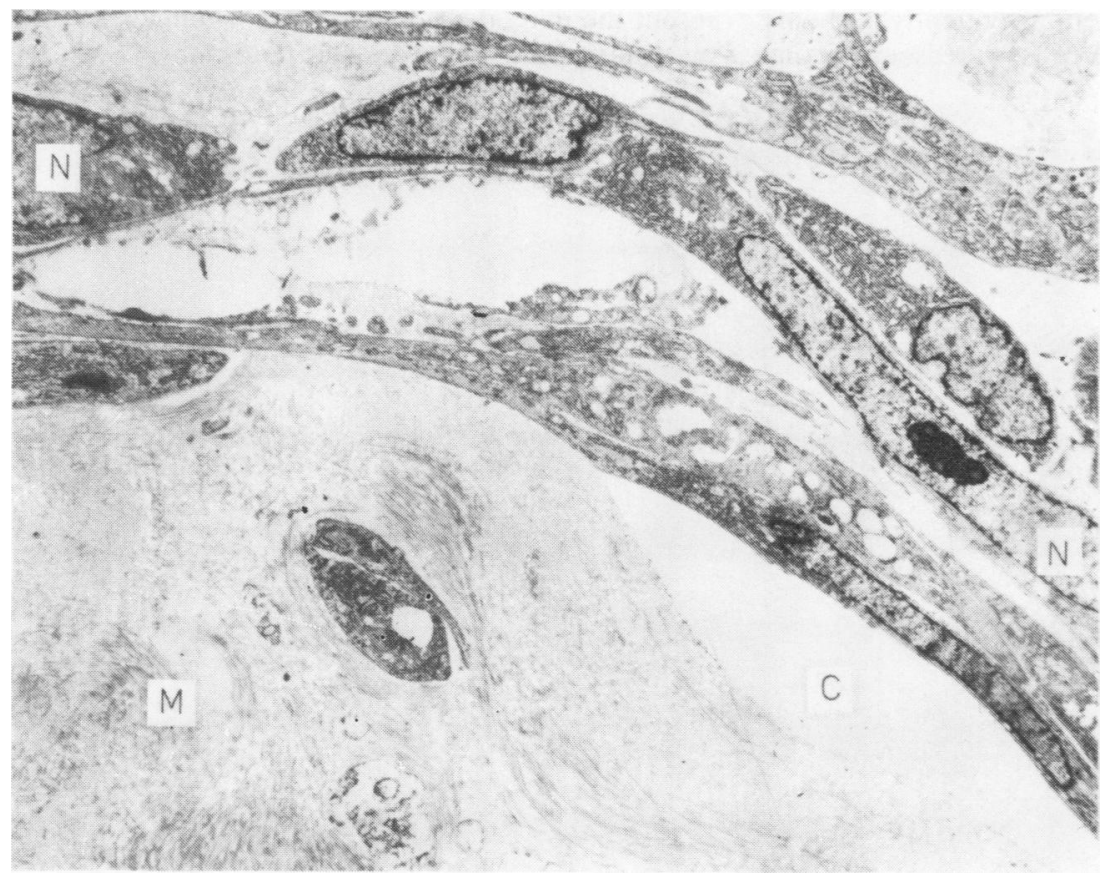

Fig. 4 Spindle cells in a collagenous matrix (M) showing ovoid and convoluted nuclei $(N)$. Clefts are visible between the cells and the collagen (C). $\times 1900$. 


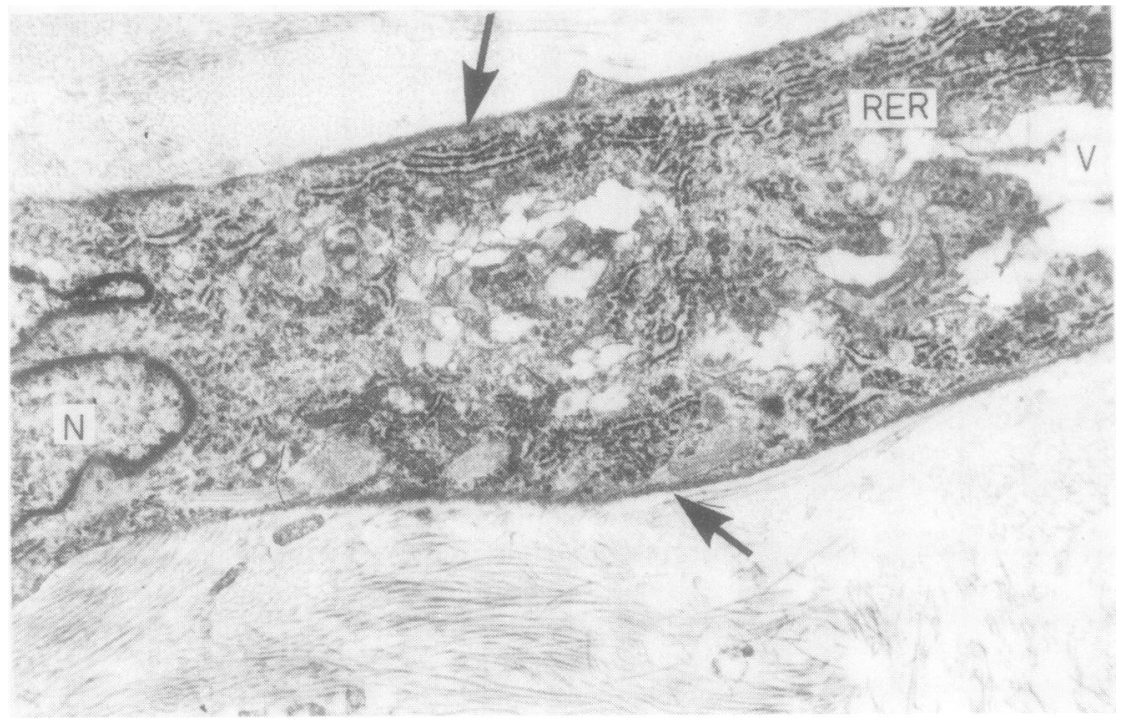

Fig. 5 Spindle cell with a convoluted nucleus $(N)$, rough endoplasmic reticulum (RER), vacuoles $(V)$, and a thin band of myofilaments just beneath the plasma membrane (arrows). $\times 5400$.

fibrous histiocytoma was relatively straightforward since myxoid change and extravasations of erythrocytes (features of the former) and a storiform pattern (a feature of the latter) were inconspicuous findings. In addition lesions were lobulated and not nodular. The circumscribed margins of the lesions tended to exclude fibromatosis. None of the lesions was considered to exhibit sufficient evidence to support the diagnosis of localised nodular tenosynovitis. Foam cells were never seen, siderophages were only noted in three cases and then infrequently and only a few multinucleated giant cells were seen in one case. However the possibility must still be admitted that the lesions denoted as fibroma of tendon sheath might represent an endstage of a nodular tenosynovitis.

The ultrastructural characteristics of fibroma of tendon sheath have not been previously described. A study of two cases in the present series revealed identical features. Ultrastructurally open clefts occurred between the collagen and cells and between cells. These were considered probably to represent the dilated slit-like vascular channels likened by Chung and Enzinger to tenosynovial spaces.

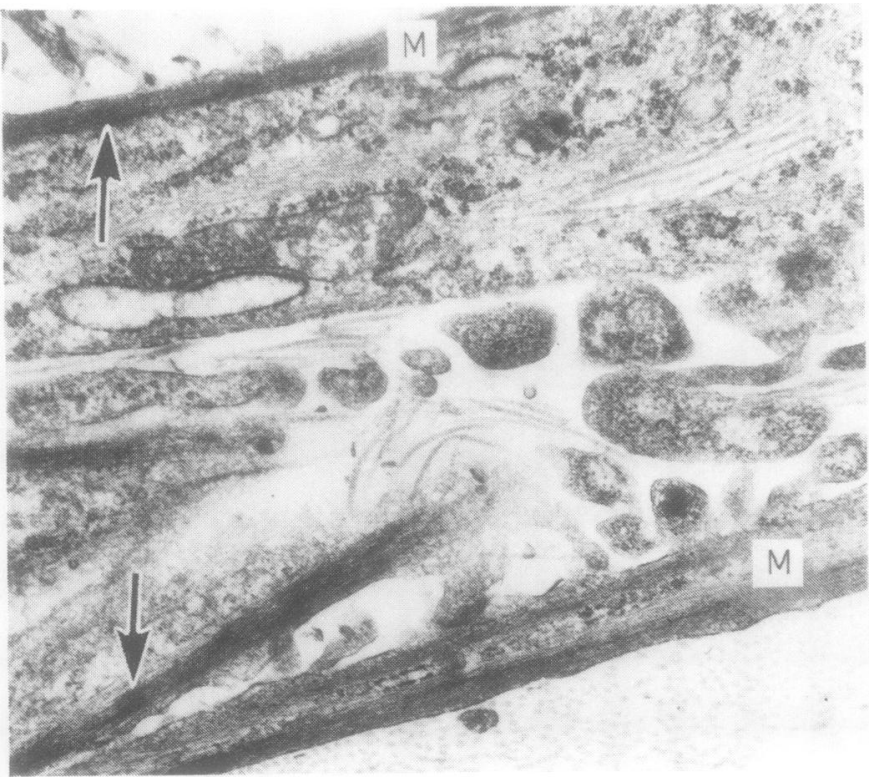

Fig. 6 Higher power view of myofilament bundles $(M)$ showing periodic densities (arrows). $\times 26200$. 


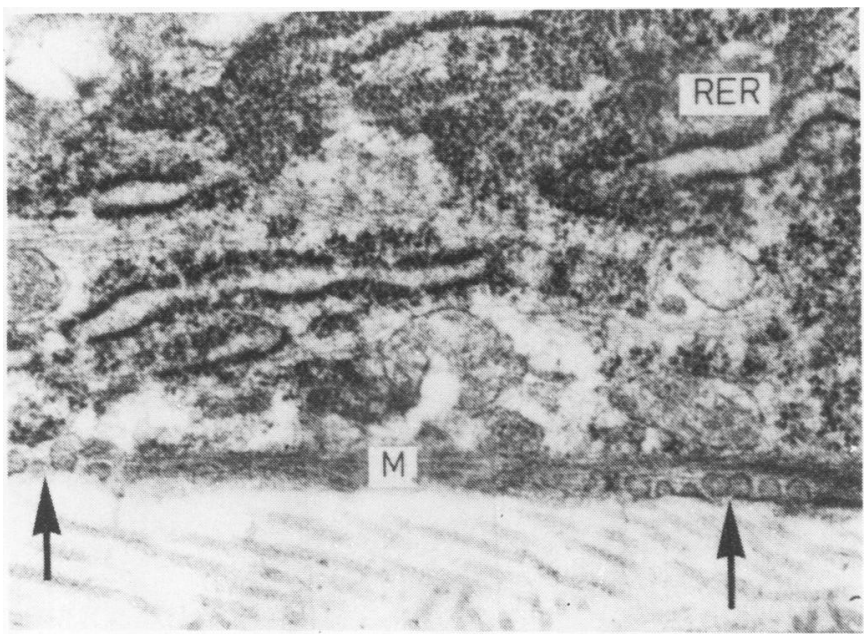

Fig. 7 Portion of spindle cell showing rough endoplasmic reticulum (RER), myofilaments $(M)$ and pinocytotic vesicles (arrows). $\times$ 12500 .

From our studies it is evident that these spaces were not vascular channels. There was no basement membrane and often there was no cell cytoplasm bounding the edge of the collagen. The spaces were devoid of red blood cells.

Of particular interest was the nature of the cells observed intrastructurally. Fibroblasts were seen rarely. These were elongated cells characterised by a smooth elongated nucleus, moderate to large amounts of rough endoplasmic reticulum (often dilated) and small numbers of other organelles including fine cytoplasmic filaments. The majority of cells seen were myofibroblasts. These cells combine the features of fibroblasts and smooth muscle cells. They exhibit nuclear indentations and folds, bundles of intracytoplasmic microfilaments arranged parallel to the long axis of the cell and dense bodies similar to those in smooth muscle cells, surface differentiations with desmosomes and hemidesmosomes, abundant rough endoplasmic reticulum and pinocytotic vesicles. 5

Myofibroblasts has been described in a variety of lesions. These include granulation tissue, ${ }^{5}$ atheromatous plaques, ${ }^{6}$ ganglia, ${ }^{7}$ hepatic cirrhosis, ${ }^{8}$ triggering tenosynovitis, ${ }^{9}$ Dupuytren's contracture, ${ }^{10}$ desmoid fibromatosis, ${ }^{11}$ circumscribed fibromatosis ${ }^{12}$ and nodular fasciitis. ${ }^{13}$

As has been pointed out by Vasudev and Harris ${ }^{14}$ few reports exist of myofibroblasts occurring in true neoplasms. They refer to six documented cases of malignant tumours which contained myofibroblasts and which had been classified as fibrosarcomas. With regard to benign tumours nine cases of typical dermatofibroma have been shown to contain myofibroblasts. ${ }^{15} \mathrm{~A}$ giant cell fibroma of the oral mucosa has also been reported to contain myofibroblasts. ${ }^{16}$ If it is accepted that fibroma of tendon sheath is a true benign neoplasm then it is an example of a tumour of myofibroblasts.

The nature and significance of these cells have been discussed by Ryan et $\mathrm{al}^{5}$ and Vasudev and Harris. ${ }^{14}$ The former have suggested that myofibroblasts arise locally from more conventional fibroblasts or from primitive mesenchymal cells. Fibroblasts cultured in vitro develop intracytoplasmic fibrillar systems similar to those of myofibroblasts. ${ }^{17}$ Vasudev and Harris suggest that myofibroblasts represent the expression of a limited potential in fibroblasts for differentiation along myoid lines and that the development of microfilaments is the normal reaction to a variety of proliferative stimuli.

We wish to thank Mrs L Murray and Miss R Noble who prepared the EM sections and Mrs C Wickremasuriya for typing the manuscript.

\section{References}

' Buxton St JD. Tumours of tendon and tendon sheath. Br J Surg 1923;10:469-74.

${ }^{2}$ Alguacil-Garcia A, Unni KK, Goellner JR. Giant cell tumour of tendon sheath and pigmented villonodular synovitis: an ultrastructural study. Am J Clin Pathol 1978;69:6-7.

${ }^{3}$ Geschickter CF, Copeland MM. Tumours of bone. Philadelphia: JB Lippincott, 1949.

4 Chung EB, Enzinger FM. Fibroma of tendon sheath. Cancer 1979;44:1945-54.

s Ryan GB, Cliff WJ, Gabbiani G, Irlé C, Montandon D, Statkov PR, Majno G. Myofibroblasts in human granulation tissue. Hum Pathol 1974;5:55-67.

- Geer JC. Fine structure of human aortic intimal thickening and fatty streaks. Lab Invest $1965 ; 14: 1764-83$.

${ }^{7}$ Ghadially FN, Mehta PN. Multifunctional mesenchymal cells resembling smooth muscle cells in ganglia of the wrist. Ann Rheum Dis 1971;30:31-42.

- Bhathal PS. Presence of modified fibroblasts in cirrhotic livers in man. Pathology 1972;4:139-44. 
${ }^{9}$ Madden JW. The contractile fibroblast. Plast Reconstr Surg 1973;52:291-2.

${ }^{10}$ Gabbiani G, Majno G. Dupuytren's contracture: fibroblast contraction? An ultrastructural study. Am J Pathol 1972;66: $131-46$.

"Stiller D, Katenkamp D. Cellular features in desmoid fibromatosis and well differentiated fibrosarcomas. An electron microscopy study. Virchows Arch Pathol Anat Histol 1975;367:155-64.

${ }^{12}$ Feiner H, Kaye GI. Ultrastructural evidence of myofibroblasts in circumscribed fibromatosis. Arch Pathol Lab Med 1976;100: 265-8.

${ }^{13}$ Wirman JA. Nodular fasciitis, a lesion of myofibroblasts. An ultrastructural study. Cancer 1976;38:2378-89.
14 Vasudev KS, Harris M. A sarcoma of myofibroblasts. An ultrastructural study. Arch Pathol Lab Med 1978;102:185-8.

${ }^{15}$ Katenkamp D, Stiller D. Cellular composition of so-called dermatofibroma (histiocytoma cutis). Virchows Arch Pathol Anat Histol 1975;367:325-36.

${ }^{16}$ Weathers DR, Campbell WG. Ultrastructure of giant cell fibroma of the oral mucosa. Oral Surg 1974;38:550-61.

17 Goldberg B, Green H. An analysis of collagen secretion by established mouse fibroblast lines. J Cell Biol 1964;22:227-58.

Requests for reprints to: Dr J McClure, IMVS, Box 14 Rundle Street PO, Adelaide, South Australia 5000. 